\title{
Muscles, Ligaments and Tendons Journal - Basic principles and recommendations in clinical and field Science Research: 2016 Update
}

\author{
Johnny Padulo1,2 \\ Francesco Oliva ${ }^{3}$ \\ Antonio Frizziero 4 \\ Nicola Maffulli5,6 \\ 1 University e-Campus, Novedrate, Italy \\ 2 Faculty of Kinesiology, University of Split, Split, \\ Croatia \\ 3 Department of Orthopaedics and Traumatology, \\ University of Rome "Tor Vergata", Rome, Italy \\ 4 Department of Physical and Rehabilitation Medi- \\ cine, University of Padua, Padua, Italy \\ 5 Head of Department of Orthopaedic and Trauma \\ Surgery, University of Salerno, Italy \\ 6 Centre for Sports and Exercise Medicine, Queen \\ Mary University of London Bart and The London \\ School of Medicine and Dentistry, Mile End Hospital \\ London, UK
}

Corresponding author:

Johnny Padulo

University e-Campus

Via Isimbardi, 10

22060 Novedrate, Italy

E-mail: sportcinetic@gmail.com

\section{Summary}

The proper design and implementation of a study as well as a balanced and well-supported evaluation and interpretation of its main findings are of crucial importance when reporting and disseminating research. Also accountability, funding acknowledgement and adequately declaring any conflict of interest play a major role in science. Since the Muscles, Ligaments and Tendons Journal (MLTJ) is committed to the highest scientific and ethical standards, we encourage all Authors to take into account and to comply, as much as possible, to the contents and issues discussed in this official editorial. This could be useful for improving the quality of the manuscripts, as well as to stimulate interest and debate and to promote constructive change, reflecting upon uses and misuses within our disciplines belonging to the field of "Clinical and Sport - Science Research".

KEY WORDS: best practice, conflict of interest, design, experimental approach, ethical standard, statement, evidence-based medicine.
In the last two years, research opportunities, approaches and environment have been rapidly evolving as well as associated ethical issues. In the original 2014 Muscles, Ligaments and Tendons Journal (MLTJ) editorial ${ }^{1}$, we described the best research practices, taking into consideration ethical aspects and international laws, providing a specific guideline for researchers working within the vast, interdisciplinary field of "Clinical and Sport - Science Research". Experiments are routinely designed and collected from investigators for various purposes, but, unfortunately, are sometimes reported with a lack of details that could, instead, facilitate their reproducibility; therefore, the current Update specifically refers to:

1. the most important ethical guidelines in the field of sports sciences, with a focus on the Declaration of Helsinki and its amendments over the years;

2. investigations involving human subjects, and in particular young participants and children;

3. investigations involving animals;

4. investigations involving the use of cell-lines;

5. investigations involving the use of bio-banks;

6. investigations involving subjects in studies concerning doping agents;

7. investigations involving deception;

8. recommendations for studies reporting results obtained from basic science;

9. evidence-based medicine;

10. guideline for standardizing and reporting "walking and running studies/vibration treatment/muscular activity analysis/clinical stabilometry standardization/aerobic - anaerobic exercises".

\section{Sports ethics}

Ethical issues in sports medicine and, more generally speaking, in sports sciences, are unique ${ }^{2}$; because of the same sports context, being highly competitive and demanding, which may put the doctor under pressure. Further, the presence of the triad physician-patient-team ${ }^{3}$ has replaced the typical dyad doctor-patient and this implies a not easy balance between the single athlete's interest and the team's interest ${ }^{2}$. For example, conflicts may arise when doctor has to decide about return to play of the athlete ${ }^{4}$ the team could influence the clinician and force him to opt for a premature return of the athlete. Scientific research is of crucial importance in that can support clinicians, providing scientific evidences and assisting their deci- 


\section{J. Padulo et al.}

sion-making process, as we will discuss in the following paragraphs and sections.

\section{Ethical guidelines}

The most important ethical guidelines in the field of sports sciences are listed in Table 1. Other outstanding ethical codes are those of the United Nations Educational, Scientific and Cultural Organization (UN$\mathrm{ESCO})^{5}$, the International Federation of Sports Medicine (IFSM) Fédération Internationale de Médecine du Sport (FIMS) ${ }^{6}$, among others.

\section{Declaration of Helsinki}

Among ethical guidelines, declaration of Helsinki represents an undoubtedly milestone ${ }^{7}$. The World Medical Association (WMA) has revised the Declaration of Helsinki, which in its latest version ensures increased protection for people taking part in medical research, and in particular for vulnerable groups. Table 2 shows the various amendments that have occurred since inception.

\section{Research involving human participants}

Research involving human subjects should:

- respect the participant's rights, safety and wellbeing;

- be approved by an appropriate ethical committee;

- have a clearly justifiable and properly developed experimental approach (design - statistical analysis), in accordance with the Declaration of Helsinki;

- provide information regarding "funding - sponsor - other potential conflicts of interest (which should be clarified and detailed);

- an adequate compensation and treatment for each participant.

\section{Research involving young participants}

- For subjects aged $<18$ years, the informed consent/assent should be provided with appropriate, written documentation by parent/guardian/tutor;

- informed consent (also for adults) should be exhaustive, clearly readable ${ }^{8}$;

Table 1. The most important ethical guidelines in the field of sports sciences.

\begin{tabular}{ll}
\hline Year & Ethical guidelines \\
\hline 1947 & Nuremberg Code \\
1964 -on (last revised 2013) & Declaration of Helsinki \\
1981 -on (last revised 2010) & $\begin{array}{l}\text { World Medical Association Declaration on Principles of Health Care for Sports Medi- } \\
\text { cine }\end{array}$ \\
2009 -on & Olympic Movement Medical Code \\
\hline
\end{tabular}

Table 2. A historical outline of the development of the Declaration of Helsinki.

\begin{tabular}{|c|c|}
\hline Year & Version and changes \\
\hline 1964 (June) & $1^{\text {st }}$ version, adopted by the $18^{\text {th }}$ WMA General Assembly, Helsinki, Finland \\
\hline 1975 (October) & $\begin{array}{l}1^{\text {st }} \text { revision, adopted by the } 29^{\text {th }} \text { WMA General Assembly, Tokyo, Japan. Approval of the research by an } \\
\text { independent Institutional Review Board (IRB); greater emphasis on subject's safety and well-being }\end{array}$ \\
\hline 1983 (October) & $\begin{array}{l}2^{\text {nd }} \text { revision, adopted by the } 35^{\text {th }} \text { WMA General Assembly, Venice, Italy. Seeking the consent of minors, } \\
\text { where possible }\end{array}$ \\
\hline 1989 (September) & $3^{\text {rd }}$ revision, adopted by the $41^{\text {st }}$ WMA General Assembly, Hong Kong. Greater importance to IRBs \\
\hline 1996 (October) & $\begin{array}{l}4^{\text {th }} \text { revision, adopted by the } 48^{\text {th }} \text { WMA General Assembly, Somerset West, Republic of South Africa. } \\
\text { Great emphasis on placebo and standard of care }\end{array}$ \\
\hline 2000 (October) & $\begin{array}{l}5^{\text {th }} \text { revision, adopted by the } 52^{\text {nd }} \text { WMA General Assembly, Edinburgh, Scotland. Great emphasis on } \\
\text { best research practices, publication ethics and the potential impact of sponsorship }\end{array}$ \\
\hline 2002 (October) & Notes of clarification added, adopted by the $53^{\text {rd }}$ WMA General Assembly, Washington DC, USA \\
\hline 2004 (October) & Notes of clarification added, adopted by the $55^{\text {th }}$ WMA General Assembly, Tokyo, Japan \\
\hline 2008 (October) & $6^{\text {th }}$ revision, adopted by the $59^{\text {th }}$ WMA General Assembly, Seoul, Republic of Korea \\
\hline 2013 (October) & $\begin{array}{l}7^{\text {th }} \text { revision, adopted by the } 64^{\text {th }} \text { WMA General Assembly, Fortaleza, Brazil. Greater accountability, } \\
\text { transparency and patient safety }\end{array}$ \\
\hline
\end{tabular}

Abbreviations: WMA (World Medical Association). 
Muscles, Ligaments and Tendons Journal - Basic principles and recommendations in clinical and field Science Research: 2016 Update

- issues of privacy and confidentiality (also for adults) should be considered in their broader meaning, that is to say beyond what is strictly legally required (i.e., images video recording, data set with name and surname $)^{9}$;

- particular confidentiality is required when the investigator collects data at the worksite or from the Internet ${ }^{10}$. Unfortunately, the particularly challenging sports climate and environment may exacerbate pressures on clinicians to break patient confidentiality ${ }^{11}$.

\section{Research involving animals}

Research involving animals should be conducted ethically according to the principles of the Guide for the Care and Use of Laboratory Animals of the Institute for Laboratory Animal Research ${ }^{12}$, as subsequently revised and modified by the $8^{\text {th }}$ edition of the Guide for the Care and Use of Laboratory Animals, published in $2010^{13}$ and as suggested in a recently published editorial ${ }^{14}$.

The investigator should:

- acquire animals according to the extant legal statutes and regulations;

- ensure the safety and the wellbeing of the animal in terms of adequate housing, feeding, hygienic and comfortable living conditions;

- be assisted by qualified personnel;

- avoid or minimize as much as possible the suffering, discomfort and pain of the animal during the research.

\section{Investigations involving the use of cell lines}

Basic science is of crucial importance for the sports disciplines. Researchers should pay attention to the following issues ${ }^{15}$ :

- cell-line misidentification;

- cell-line contamination with microorganisms;

- cell-line instability, both genetic and phenotypic;

- cell-line development, acquisition, authentication, cryopreservation, transfer between laboratories, and characterization.

\section{Investigations involving the use of bio-banks}

Use of bio-banks in the field of sports sciences is currently limited to few studies ${ }^{16,17}$, but is increasing. The Authors should comply to the specific ethical, legal, social issues (ELSI) in vigor in their countries ${ }^{16}$.

\section{Investigations involving subjects in studies concerning doping agents}

Studies involving athletes (both recreational or elite ones) in researches concerning doping agents, practices or behaviors banned by the World Anti-Doping
Association (WADA) are particularly challenging in that are delicate. These investigations should be conducted only after the approval of anti-doping organizations, such as the WADA, paying attention not to give advantages to athletes themselves and to avoid a misuse or the results or their application for doping ${ }^{18}$.

\section{Investigations involving deception}

It has been underlined by some scholars that the current ethical guidelines are generally thought for quantitative studies and tend to overlook qualitative research. This is particularly true for investigations involving deception, such as studies on hooliganism or on sexist or racist attitudes, which have particular difficulties in obtaining the ethical clearance. As suggested by other researchers ${ }^{19}$, these investigations may be permissible if:

- are of outstanding importance and have practical implications;

- participants are not be likely to suffer physical, social, or psychological harm;

- the results could not be obtained in any other way.

\section{Recommendations for studies reporting re- sults obtained from basic science}

Studies reporting molecular/structural results obtained from basic science should report the data base accession number of the deposited amino acid sequences of proteins or the nucleotide/gene sequences. The data base name should be also detailed [for example, the European Molecular Biology Laboratory (EMBL), GenBank Data Libraries, the Worldwide Protein Data Bank (http://www.wwpdb.org), the RCSB PDB (http://www. pdb.org), the MSD-EBI (http://www.ebi.ac.uk/pdbe/), the PDBj (http://www.pdbj.org), the BMRB (http://www. bmrb.wisc.edu), or the RCSB EMDB (http://www.emdatabank.org), among others].

\section{Evidence-based medicine}

- Evidence-based medicine (EBM) is an approach based on a systematic process of review, quality assessment of the medical literature. Classifying the level and the strength of evidence of the empirical findings, it aims at helping clinicians in decision-making and at ensuring the patients an optimal level of medical care and practice at highest level possible ${ }^{20}$.

- This expression has subsequently spread to the different medical specialties and branches. As such, evidence-based physiotherapy ${ }^{21}$ and evidence-based sports medicine 22 .

- It is of crucial importance to critically appraise the study quality using grading systems. The US Preventive Services Task Force (USPSTF) has proposed the following classification: level I (evidence obtained from randomized controlled trials, RCTs, systematic reviews and/or meta-analyses); 
level II-1: evidence obtained from properly designed controlled trials not randomized; level II-2: evidence obtained from (multi-centric) cohort or case-control studies; level II-3: evidence obtained from multiple time series designs; level III: expert opinions and commentaries, consensus or descriptive studies (the so-called eminence-based medicine) ${ }^{23}$.

- The grade of recommendation can be distinguished in: grade $A$ (good scientific evidence to recommend in favor of the action); grade B (at least fair scientific evidence to recommend in favor of the action); grade $\mathrm{C}$ (conflicting scientific evidence); grade D (at least fair scientific evidence to recommend against the action); grade I (lacking or poor quality scientific evidence).

- MLTJ calls for high quality studies that can contribute to the advancement of sports medicine. A recently conducted review of the sports medicine literature has found that only $10 \%$ and $6 \%$ of articles contain Level I evidence and RCTs ${ }^{24}$.

- RCTs can be reported following the Consolidated Standards of Reporting Trials (CONSORT) guidelines 25 .

In the specific field of sports medicine, systematic reviews can be conducted consulting specific databases, such as SPORTDiscus (EBSCO), CINAHL, and Physical Education Index (CSA), and following the Preferred Reporting Items for Systematic Reviews and MetaAnalysis (PRISMA) guidelines ${ }^{26}$, modyfing Coleman methodology score according to the requirements ${ }^{27}$.

MLTJ encourages Authors to publish their protocols of systematic reviews and/or meta-analysis and to register it in the PROSPERO database (International prospective register of systematic reviews http://www. crd.york.ac.uk/PROSPERO).

\section{Specific issue relevant to the standard procedures and recommendations}

- In the era of the EBM, ensuring standardization and reproducibility is crucial. The "minimum information" standard is a new conceptual framework that comprises a set of checklists, protocols and/or guidelines for performing experiments and reporting the resultant, generated data (experimental data) along with essential information about the experiments themselves (metadata or contextual data). If followed, this data recording and reporting standard ensures that the data can be easily accessed, independently verified, analyzed and clearly, unambiguously interpreted by the scientific community. Metadata or "data about data" are, indeed, particularly important in context-sensitive experiments, in that they "capture what happens on the backstage of science, on the trajectory from study conception, design, funding, implementation, and analysis to reporting. Definitions of metadata vary, but they can include the context information surrounding the practice of science, or data generated as one uses a technology, including transactional information about the user"28.
- Unfortunately, these data are usually left to the discretion of the Authors or can be sometimes solicited and requested by the journals editors and reviewers.

- In order to standardize the Whole-body vibration studies (according to Rauch et al.)29, the following details should be necessarily included: manufactory (trademark), vibration time (sec/min), passive recovery (sec/min), frequency $(\mathrm{Hz})$, peak-to peak displacement $(\mathrm{mm})$, amplitude $(\mathrm{mm})$, peak acceleration $\left(\mathrm{ms}^{-}\right.$ $\left.{ }^{2}\right)$, root mean squared acceleration $\left(\mathrm{ms}^{-2}\right)$. For the body position (i.e. foot), optimal frequency vibration and optimal vibration load, we invite all Authors to read and to refer to Di Giminiani et al. ${ }^{30-32}$.

- In order to use a shared and standardized language on postural sway/stabilometric analysis, we invite all Authors to meet with the criteria suggested in "The clinical stabilometry standardization..." by Scoppa et al. ${ }^{33}$, based on: tool (sample rate at least $50 \mathrm{~Hz}$ ); the acquisition should not be less than $25 \mathrm{sec}$.

- For clinical and field setting the temporal pattern variables in walking and running gaits should be included for both acute and chronic effects ${ }^{34}$. Particularly, several steps must be observed: device calibration (i.e. treadmill), familiarization, warm-up, kinematic analysis, and oxygen consumption.

- In the last years, much attention and many efforts have been dedicated to standardize the methodology for assessing muscular activity. For example, the Surface Electromyography (EMG) for the Non-Invasive Assessment of Muscles (SENIAM) project has put for recommendations that should reduce variability and increase reproducibility, ensuring a major exchange and reuse of data, and, as such, greater co-operation and collaboration among researchers $^{35}$ : the choice of the sensor and its surface electrode (measure - $\mathrm{mm} / \mathrm{cm}$ ), the choice of the muscle and the placement of sensors, the signal processing in terms of sample rate of the EMG device (up $1500 \mathrm{~Hz}$ ), and data analysis (i.e., root mean squared) ${ }^{36}$, EMG normalization (\% of maximal voluntarily contraction $)^{37}$, among others.

- Based on exercise physiology, we stimulate all researchers to appropriately use aerobic and anaerobic terms ${ }^{38}$ to describe the several degrees of exercise intensity: namely, 'Explosive Efforts' (in case duration is up to $6 \mathrm{sec}$ ), 'High Intensity Efforts' (efforts comprised between $>6 \mathrm{sec}$ and $1 \mathrm{~min}$ ), and 'Endurance Intensive Efforts' (for exercise bouts longer than $1 \mathrm{~min}$ ).

Authors are required to confirm (after read and turn up the first guideline $)^{1}$ their compliance to the ethical and scientific standards here discussed, by formally citing this editorial within the methods section of their own manuscript. Further, MLTJ welcomes methodological papers, which address to solve those key issues that hamper widespread use of techniques in the field of "Clinical and Sport - Science Research".

\section{Acknowledgement}

We would linke to express the deep appreciation to 
Muscles, Ligaments and Tendons Journal - Basic principles and recommendations in clinical and field Science Research: 2016 Update

MD Nicola Luigi Bragazzi for the endless support for this document

\section{Conflict of interests}

The Authors declare that they have no conflict of interests regarding the publication of this paper.

\section{References}

1. Padulo J, Oliva F, Frizziero A, Maffulli N. Muscles, Ligaments and Tendons Journal. Basic principles and recommendations in clinical and field science research. MLTJ. 2013;3(4):250252.

2. Tucker AM. Ethics and the professional team physician. Clin Sports Med. 2004;23(2):227-241.

3. Devitt BM. Fundamental Ethical Principles in Sports Medicine. Clin Sports Med. 2016;35(2):195-204.

4. Kroshus E, Baugh CM, Daneshvar DH, Stamm JM, Laursen RM, Austin SB. Pressure on Sports Medicine Clinicians to Prematurely Return Collegiate Athletes to Play After Concussion. J Athl Train. 2015;50(9):944-951.

5. UNESCO. http://portal unesco org/education/en/ev phpURL_ID $=2223 \& U R L$ DO=DO_TOPIC\&URL_SECTION=201 html 2016.

6. FIMS. www fims org/about/code-ethics/ 2016.

7. Stewart RJ, Reider B. The Ethics of Sports Medicine Research. Clin Sports Med. 2016;35(2):303-314.

8. Cardinal BJ, Martin JJ, Sachs ML. Readability of written informed consent forms used in exercise and sport psychology research. Res Q Exerc Sport. 1996;67(3):360-362.

9. Anderson L. Contractual obligations and the sharing of confidential health information in sport. J Med Ethics. 2008;34 (9):e 6.

10. Shephard RJ. Ethics in exercise science research. Sports Med. 2002;32(3):169-183

11. Malcolm D. Confidentiality in Sports Medicine. Clin Sports Med. 2016;35(2):205-215.

12. Institute for Laboratory Animal Research, National Research Council. Guide for the Care and Use of Laboratory Animals. Washington. D C: National Academy Press. 1996;140.

13. Institute for Laboratory Animal Research, National Research Council. Guide for the Care and Use of Laboratory Animals. Washington, D C: National Academy Press. 2010;248.

14. Harriss DJ, Atkinson G. Ethical standards in sport and exercise science research: 2014 update. Int J Sports Med. 2013;34(12): 1025-1028.

15. Geraghty RJ, Capes-Davis A, Davis JM, et al. Guidelines for the use of cell lines in biomedical research. Br J Cancer. 2014; 111(6):1021-1046.

16. Du H, Li L, Whitlock G, et al. Patterns and socio-demographic correlates of domain-specific physical activities and their associations with adiposity in the China Kadoorie Biobank study. BMC Public Health. 2014;14:826.

17. Xu L, Jiang CQ, Lam TH, Zhang WS, Thomas GN, Cheng KK. Dose-response relation between physical activity and cognitive function: guangzhou biobank cohort study. Ann Epidemiol. 2011;21(11):857-863.

18. Howman D. Scientific research using elite athletes: WADA point of view. J Appl Physiol (1985). 2013;114(10):1365.

19. Olivier S, Fishwick L. Qualitative Research in Sport Sciences: Is the Biomedical Ethics Model Applicable? Forum Qualitative Sozialforschung/Forum: Qualitative Social Research. http://www qualitative-research net/index php/fqs/article/ view/754/1634. 2003;4(1).
20. Rosenberg W, Donald A. Evidence based medicine: an approach to clinical problem-solving. BMJ. 1995; 310(6987): $1122-1126$

21. Bithell C. Evidence-based Physiotherapy: Some thoughts on 'best evidence'. Physiotherapy. 2000;86(2):58-59.

22. McCrory P. Evidence-based sports medicine. Br J Sports Med. 2001;35(2):79-80.

23. Tjoumakaris FP, Ganley TJ, Kapur R, Kelly J, Sennett BJ, Bernstein J. Eminence-based medicine versus evidencebased medicine: level $\mathrm{V}$ evidence in sports medicine. Phys Sportsmed. 2011;39(4):124-130.

24. Harris JD, Cvetanovich G, Erickson BJ, et al. Current status of evidence-based sports medicine. Arthroscopy. 2014;30(3): 362-371.

25. Turner L, Shamseer L, Altman DG, et al. Consolidated standards of reporting trials (CONSORT) and the completeness of reporting of randomised controlled trials (RCTs) published in medical journals. Cochrane Database Syst Rev. 2012;14(11): 30.

26. Moher D, Liberati A, Tetzlaff J, Altman DG. Preferred reporting items for systematic reviews and meta-analyses: the PRISMA statement. BMJ. 2009;339:b2535.

27. Coleman BD, Khan KM, Maffulli N, Cook JL, Wark JD. Studies of surgical outcome after patellar tendinopathy: clinical significance of methodological deficiencies and guidelines for future studies. Victorian Institute of Sport Tendon Study Group. Scand J Med Sci Sports. 2000;10(1):2-11.

28. Ozdemir V, Kolker E, Hotez PJ, et al. Ready to put metadata on the post-2015 development agenda? Linking data publications to responsible innovation and science diplomacy. OMICS. 2014; 18(1):1-9.

29. Rauch F, Sievanen H, Boonen S, Cardinale M, Degens H, Felsenberg $D$ et al. Reporting whole-body vibration intervention studies: recommendations of the International Society of Musculoskeletal and Neuronal Interactions. J Musculoskelet Neuronal Interact. 2010;10(3):193-198.

30. Di Giminiani R, Masedu F, Padulo J, Tihanyi J, Valenti M. The EMG activity-acceleration relationship to quantify the optimal vibration load when applying synchronous whole-body vibration. J Electromyogr Kinesiol. 2015;25(6):853-859.

31. Di Giminiani R, Masedu F, Tihanyi J, Scrimaglio R, Valenti M. The interaction between body position and vibration frequency on acute response to whole body vibration. J Electromyogr $\mathrm{Ki}$ nesiol. 2013;23(1):245-251.

32. Di Giminiani R, Manno R, Scrimaglio R, Sementilli G, Tihanyi $J$. Effects of individualized whole-body vibration on muscle flexibility and mechanical power. J Sports Med Phys Fitness. 2010;50(2):139-151

33. Scoppa F, Capra R, Gallamini M, Shiffer R. Clinical stabilometry standardization: basic definitions-acquisition intervalsampling frequency. Gait Posture. 2013;37(2):290-292.

34. Padulo J, Chamari K, Ardigò LP. Walking and running on treadmill: the standard criteria for kinematics studies. Muscles Ligaments Tendons J. 2014;4(2):159-162.

35. Hermens HJ, Freriks B, Disselhorst-Klug C, Rau G. Development of recommendations for SEMG sensors and sensor placement procedures. J Electromyogr Kinesiol. 2000;10(5): 361-374.

36. Bosco C, Cardinale M, Tsarpela O. Influence of vibration on mechanical power and electromyogram activity in human arm flexor muscles. Eur J Appl Physiol Occup Physiol. 1999;79 (4):306-311.

37. Padulo J, Tiloca A, Powell D, Granatelli G, Bianco A, Paoli A EMG amplitude of the biceps femoris during jumping compared to landing movements. Springerplus. 2013;2:520.

38. Chamari K, Padulo J. 'Aerobic' and 'Anaerobic' terms used in exercise physiology: a critical terminology reflection. Sports Medicine - Open. 2015;1(9):1-4 